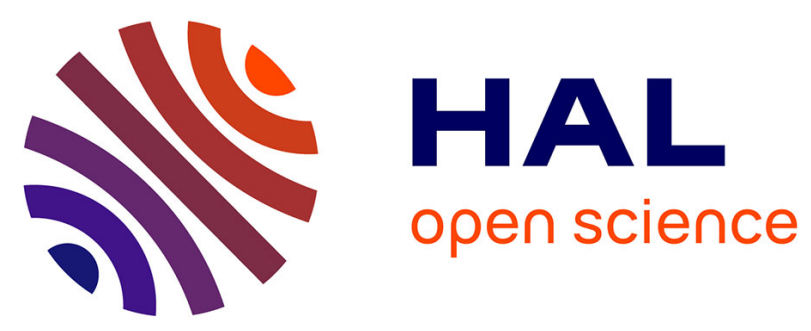

\title{
A Bi-stable Micro-machined Piezoelectric Transducer for Mechanical to Electrical Energy Transformation
}

Karim Dogheche, B. Cavallier, P. Delobelle, L. Hirsinger, Eric Cattan, Denis

Remiens, M. Marzencki, B. Charlot, Skandar Basrour, S. Ballandras

\section{- To cite this version:}

Karim Dogheche, B. Cavallier, P. Delobelle, L. Hirsinger, Eric Cattan, et al.. A Bi-stable Micromachined Piezoelectric Transducer for Mechanical to Electrical Energy Transformation. Integrated Ferroelectrics, 2006, 80, pp.305-315. 10.1080/10584580600659878 . hal-00135742

\section{HAL Id: hal-00135742 \\ https://hal.science/hal-00135742}

Submitted on 7 Jun 2021

HAL is a multi-disciplinary open access archive for the deposit and dissemination of scientific research documents, whether they are published or not. The documents may come from teaching and research institutions in France or abroad, or from public or private research centers.
L'archive ouverte pluridisciplinaire HAL, est destinée au dépôt et à la diffusion de documents scientifiques de niveau recherche, publiés ou non, émanant des établissements d'enseignement et de recherche français ou étrangers, des laboratoires publics ou privés. 


\title{
A Bi-Stable Micro-Machined Piezoelectric Transducer for Mechanical to Electrical Energy Transformation
}

\author{
K. Dogheche, ${ }^{1, *}$ B. Cavallier, ${ }^{1}$ P. Delobelle, ${ }^{1}$ L. Hirsinger, ${ }^{1}$ E. Cattan, ${ }^{2}$ \\ D. Rèmiens, ${ }^{2}$ M. Marzencki, ${ }^{3}$ B. Charlot, ${ }^{3}$ S. Basrour, ${ }^{3}$ and S. Ballandras ${ }^{1}$ \\ ${ }^{1}$ Institut FEMTO-ST, UMR CNRS 6174, (UFC-ENSMM-UTBM) 32 Avenue de \\ l'Observatoire, F-25044 Besançon, Cedex \\ ${ }^{2}$ IEMN, UMR CNRS, Dépt. DOAE-MIMM, Villeneuve d'Ascq, Cedex \\ ${ }^{3}$ TIMA Laboratory, 46, avenue Félix Viallet, 38031 Grenoble, France
}

\begin{abstract}
The development of micro-machined ultrasonic transducers on silicon opens new application fields for Si-based acoustic sensors operating in air or in liquids. In this work, we describe the fabrication of piezoelectric micro-machined ultrasonic transducers (pMUT) first dedicated to ultrasonic imaging applications that may be used as a mechanical to electrical energy transformer for energy scavenging purpose [1]. We report on the fabrication of PZT/Si piezoelectric micro-machined ultrasonic transducers (pMUTs) first designed for acoustic applications and on tests of these devices as scavenging energy experiment.
\end{abstract}

Keywords: MicroPowerGenerators; scavenging energy; energy conversion; pMUT; bistable device

\section{INTRODUCTION}

The development of bimorph structures composed of a thin piezoelectric film deposited atop a silicon membrane [2] receives an increasing interest thanks to the rapid progress in the growth of high quality material using different process (sputtering, laser ablation, chemical vapour deposition, and so on). One of the principal expected application of such devices is ultrasonic imaging, because of the possibility to fabricate dense arrays of transducers, potentially compatible 
with 3D imaging and phased-array techniques. A wide variety of applications can be characterized as either ultrasound sensing modalities like nondestructive evaluation (NDE) or ultrasound actuating modalities like medical therapy. In this work we focus on the sensing capabilities of pMUT devices for which the excitation source is mechanical (simple rotation in the gravity field or weak shake, less or equal to $2 \mathrm{~g}$ acceleration) and the sensor response is an electrical voltage loaded on a $1 \mathrm{M} \Omega$ entry impedance input high sampling-rate oscilloscope.

\section{OPERATION PRINCIPLE}

Standard acoustic transducers based on massive PZT elements usually vibrate along a fundamental compressive mode, but the pMUTs generate pressure waves thanks to a flexural vibration of a membrane consisting in a thin piezoelectric film deposited atop a silicon membrane. This configuration is advantageous for many applications as they can work on a large frequency range (a few tenth of $\mathrm{kHz}$ to several tenth of $\mathrm{MHz}$ ) and are reversible in that they can convert acoustic energy into electrical signals and vice versa, this figure being very important here. The mechanical to electrical transformer is the scavenging energy purpose. The basic structure is represented in Fig. 1.

Figure 2 shows the surface profile of one of these pMUT measured using a con-focal optical microscope. The diameter of the membrane is $600 \mu \mathrm{m}$, the

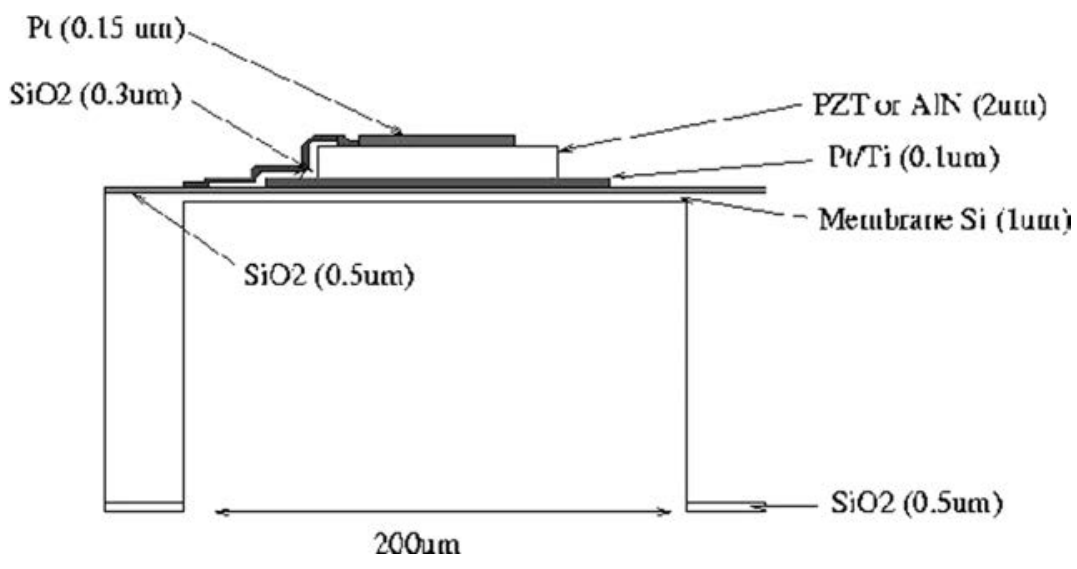

Silicon membrane thickness $=1$ to $5 \mu \mathrm{m}$

Silicon membrane diameter $=132,200,400$, and $600 \mu \mathrm{m}$ PZT thickness $=2 \mu \mathrm{m}$

Figure 1. Cross view of one pMUT cell. 


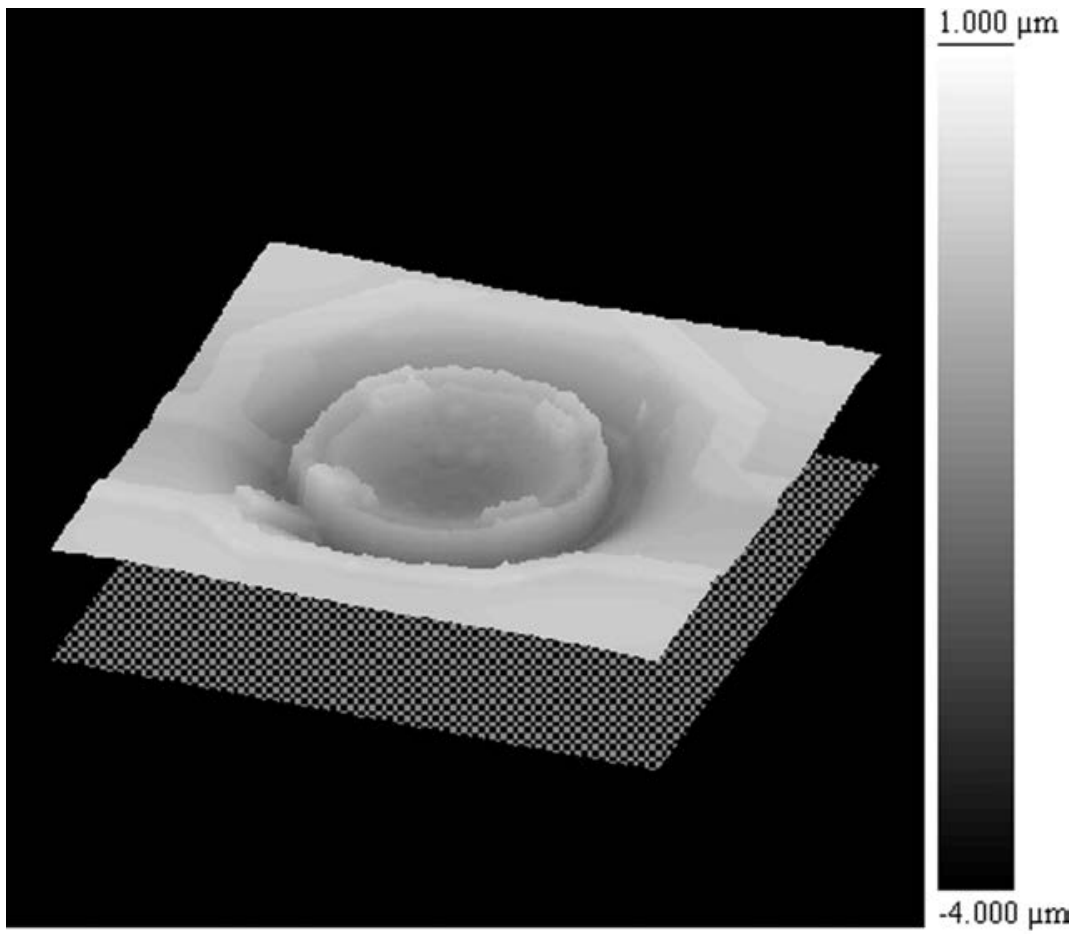

Figure 2. Surface profile of one pMUT (Continued).

silicon and PZT thickness are respectively set to 1 and $2 \mu \mathrm{m}$. This figure clearly shows that the membrane exhibit a deformed shape (the PZT is under lateral compression) with a maximum deflection equal to more than 1.5 times the equivalent membrane thickness. This signifies that the overall stress state of the device has overcome the critical limit above which the structure tends to release the stresses via a static deformation. The device then takes a stable state but may occupy another stable state corresponding to the symmetric deformation state (for which the PZT will be under lateral extension). This principle should then consist in a basic bistable device. The idea is then to test the capability of the pMUT to change from one state to the other by a simple and weak mechanical excitation (less or equal to $2 \mathrm{~g}$ acceleration).

\section{TRANSDUCERS FABRICATION}

Standard bulk silicon micromachining techniques are used to fabricate the transducers. Fabrication starts with double-side polished n-type silicon wafers. The wafers are oxidized and photolithographically patterned, leaving oxide only on 


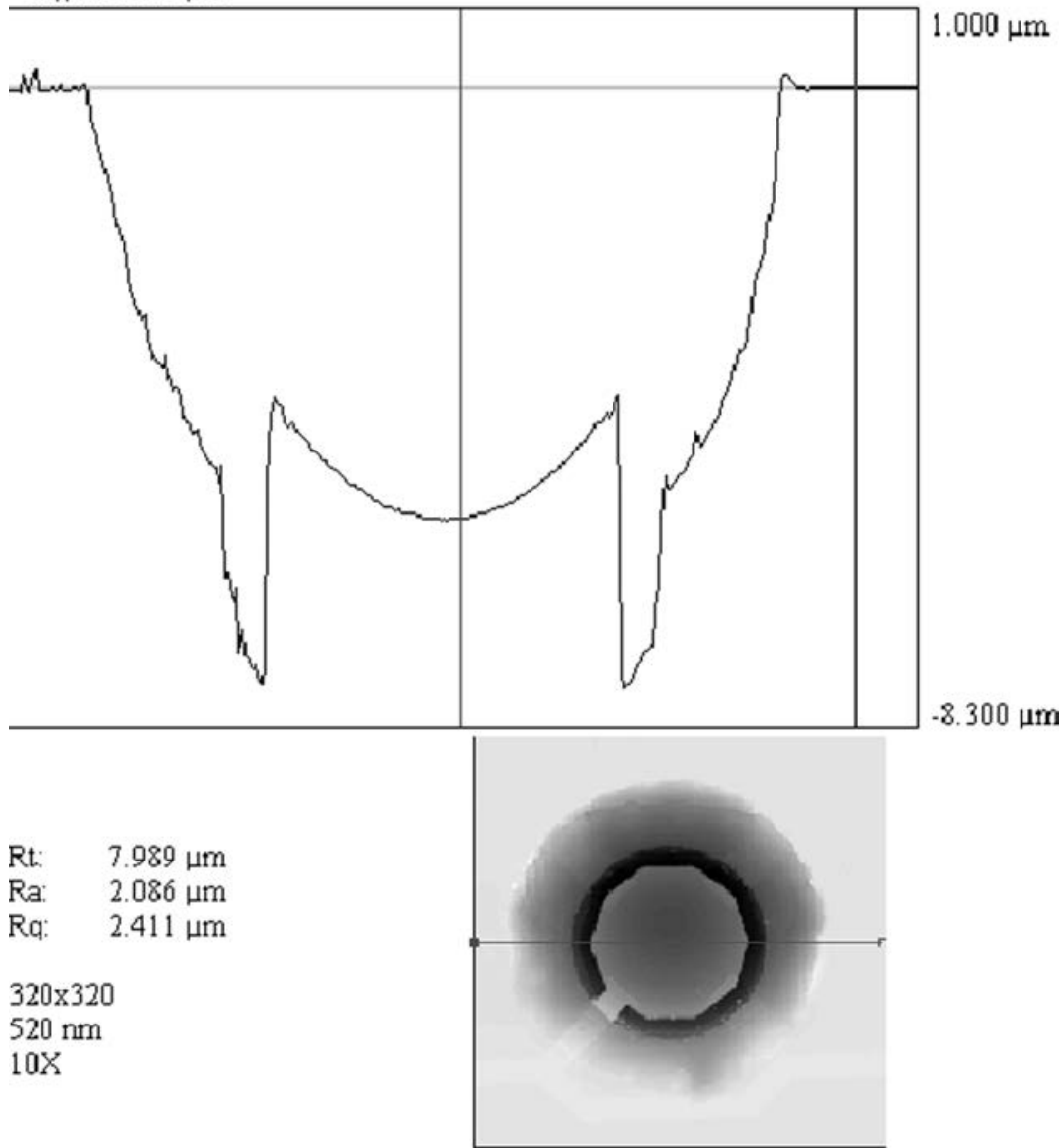

Figure 2. Continued

the wafer backs where cavities are to be etched later. A platinum electrode film on a passivated Ti adhesion layer was deposited and patterned on the wafer front surface to provide a ground plane. Lead titano-zirconate thin films have been deposited and patterned by lift-off. $\mathrm{A} \mathrm{SiO}_{2}$ interlayer between the PZT layer and the top electrode bas been deposited and patterned. A Pt/Ti top electrode has been also deposited and patterned by lift-off.

Membranes were built using deep reactive ion etching based on the Bosch process. Along this approach, it is necessary to perfectly control the fabrication 


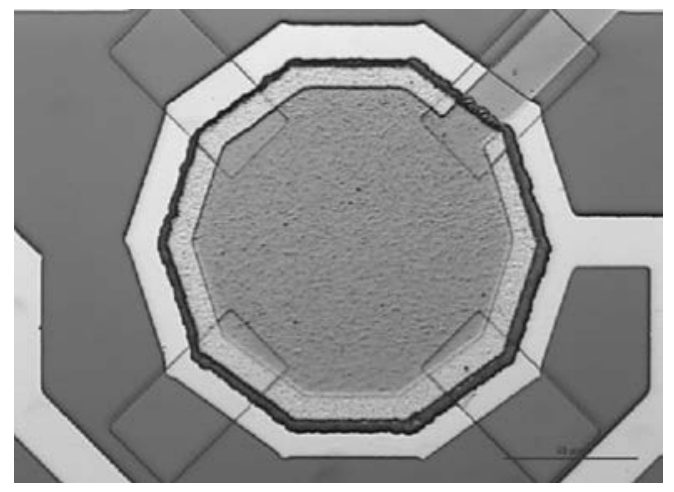

Figure 3. Example of a $200 \mu \mathrm{m}$ diameter element.

process as well as the material properties which dramatically influence the final device characteristics. Particularly, the residual stress due to thermal treatments (for instance PZT firing) or material growth and lattice mismatch may induce noticeable change in the overall material properties and final device operation. One can optimise the process to compensate those residual stresses, for instance by depositing additional layers or by thermal annealing. On the other hand, the capability of the structure to release its stress level simply by deformation has been considered here as an alternative approach which by the way can provide very attractive features for the regarded applications.

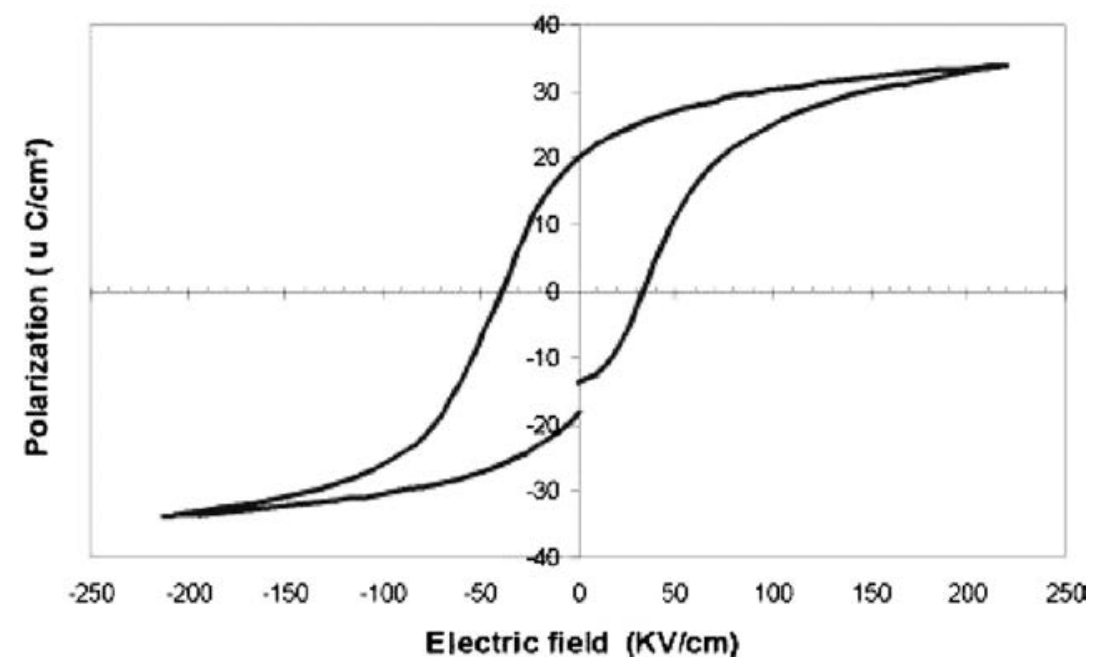

Figure 4. Ferroelectric P-E Hysterisis loop of the PZT film on membrane. 


\section{PZT PROPERTIES}

The ferroelectric nature of the PZT films was examined by observing the hysteresis loop taken at room temperature by mean of a RT 6000 system (Radian Technology). Remanent polarization and coercive field can be deduced from these hysteresis measurements. From the data in Fig. 4, remanent polarization is $20.3 \mu \mathrm{C} / \mathrm{cm}^{2}$, and coercive voltage is $30 \mathrm{KV} / \mathrm{cm}$. A poling voltage of $20 \mathrm{~V} / \mu \mathrm{m}$ as been used. Figure 4 shows a typical in-plane polarization hysteresis loop for a $2-\mu \mathrm{m}$ film.

\section{MEASUREMENTS}

We report below experimental results obtained on different silicon membrane diameters. Figures 5 to 7 give voltage responses of pMUT devices connected to a high sampling-rate oscilloscope (1 M $\Omega$ input impedance). The pMUT devices are submitted to hand shakes following an acceleration between $0.5 \mathrm{~g}$ and $2 \mathrm{~g}$. These figures give experimental results respectively for $400 \mu \mathrm{m}, 200 \mu \mathrm{m}$ and $132 \mu \mathrm{m}$ silicon membrane diameters.

Figure 5 shows different rise times that are caused by the non reproducible hand shaking excitation. We can also see on Fig. 7 different levels of voltage response and different rise times due to hand shaking excitation. The fact that we can reach different voltages shows that the response is linear which is not in

\section{Voltage response under 1 Mohm load of pMUT (400 $\mu \mathrm{m}$ Silicon membrane diameter)}

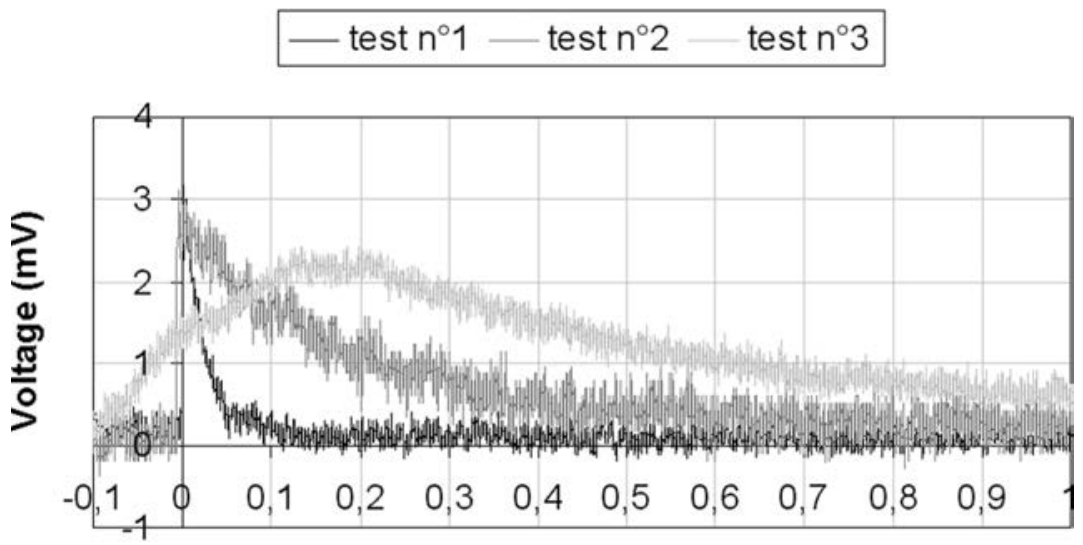

Time (ms)

Figure 5. Generated voltage response of pMUT (400 $\mu \mathrm{m}$ silicon membrane diameter). 


\section{Voltage response under $1 \mathrm{Mohm}$ load of pMUT (200 $\mu \mathrm{m}$ Silicon membrane diameter)}

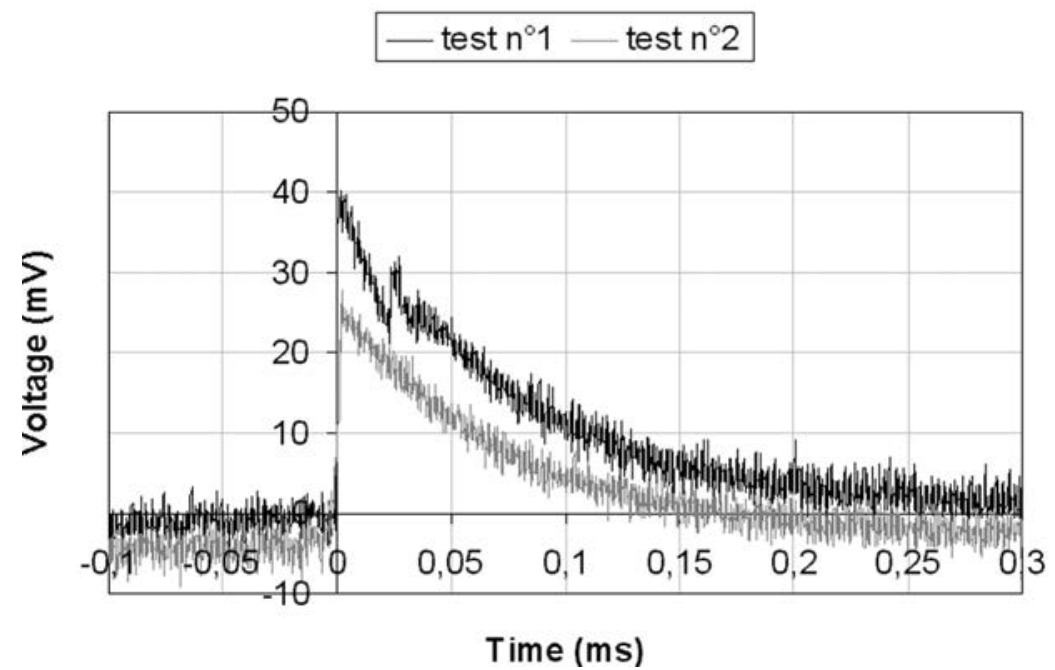

Figure 6. Generated voltage response of pMUT (200 $\mu \mathrm{m}$ silicon membrane diameter).

agreement with the bistability assumption. A bistable device is fundamentally non-linear and should give the same response as the excitation threshold is reached. Subsequently, these experiments have shown that pMUT devices have the capability to harvest energy along a linear mode (elastic behaviour).

Besides the third test on Fig. 7 shows two rising edges : the first one at time equals zero and the second one at time equals $120 \mu \mathrm{s}$. This result demonstrates two points. Fistly the pMUT device can generate electricity at a bandwidth limited to its first mode. Secondly the electrical discharge is not an issue for the dynamic behaviour of the harvesting system.

Figures 8 and 9 enable to validate the elastic behaviour of the pMUT as an energy scavenger. We have tested another pMUT element of $132 \mu \mathrm{m} \mathrm{Si}$ membrane diameter. We can see on Fig. 9 different levels of generated voltages corresponding to different levels of the mechanical excitation. The normalized results given in Fig. 9 show the same exponential decay which is characteristic of an elastic behaviour: the device dynamics do not depend on the excitation level.

The previous figures have shown great differences on the pMUT generated voltage responses that is summarized on Fig. 10. However it should be noted that no attempt was made to match impedance. Subsequently, the difference of signal levels that is shown on the above comparison (see Fig. 10) is presumably due to this impedance mismatch. Further experiments and simulations with finite 


\section{Voltage response under 1 Mohm load of pMUT (132 $\mu \mathrm{m}$ Silicon membrane diameter)}

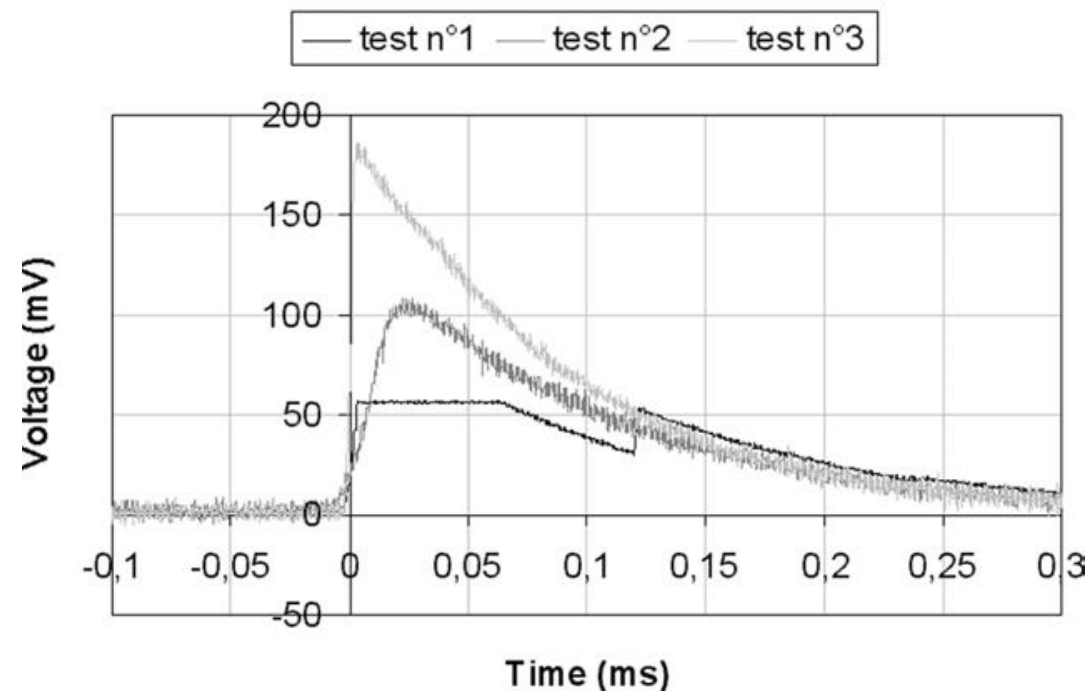

Figure 7. Generated voltage response of pMUT (132 $\mu \mathrm{m}$ silicon membrane diameter).

\section{Voltage response under 1 Mohm load of pMUT (132 $\mu \mathrm{m}$ Silicon membrane diameter, bis)}

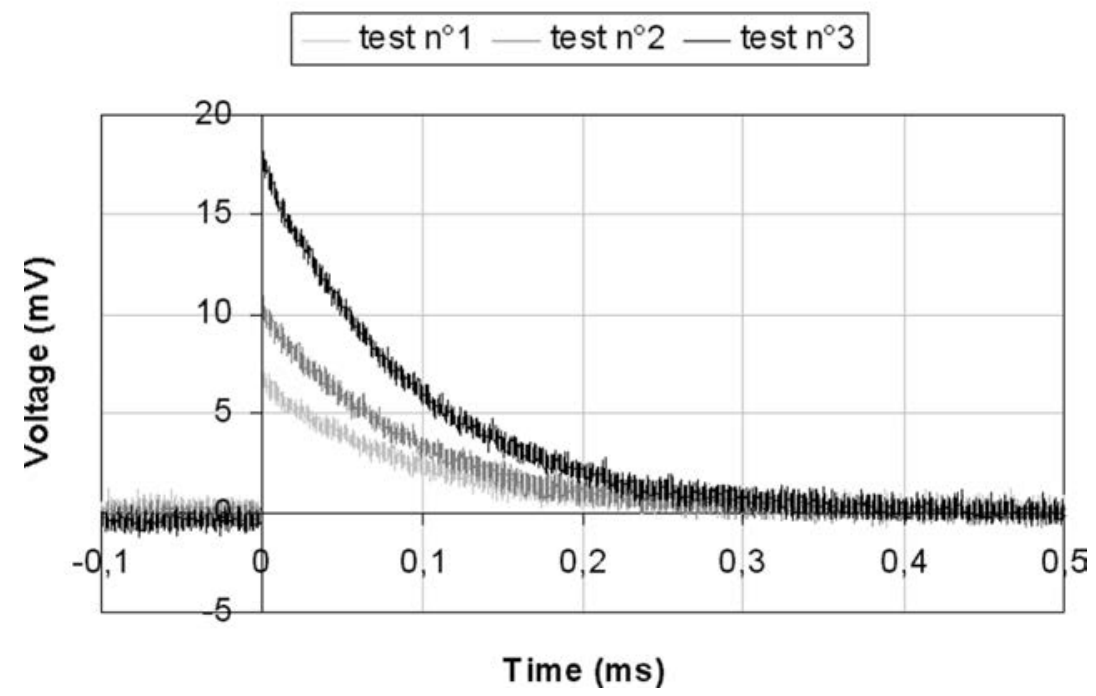

Figure 8. Generated voltage response of pMUT (132 $\mu \mathrm{m}$ silicon membrane diameter). 


\section{Normalized Voltage response under $1 \mathrm{Mohm}$ of pMUT (132 $\mu \mathrm{m}$ Si membrane diameter, bis)}

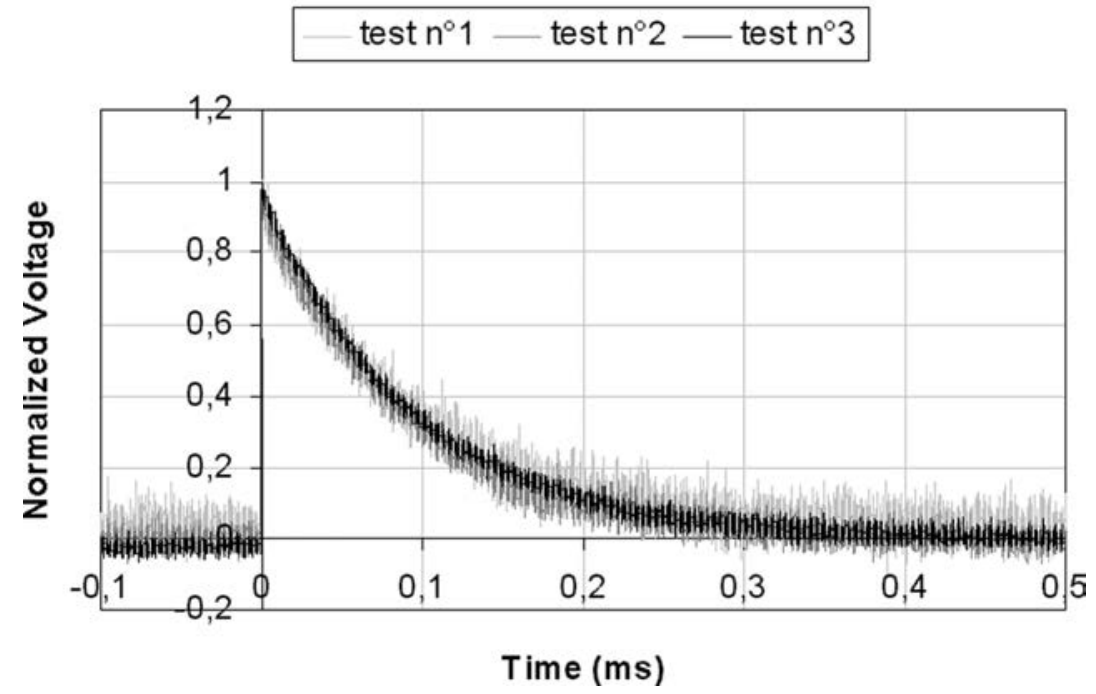

Figure 9. Generated voltage response of pMUT (132 $\mu \mathrm{m}$ silicon membrane diameter).

\section{Influence of Si membrane diameter on pMUT voltage response (under 1 Mohm load)}

$-132 \mu \mathrm{m}-200 \mu \mathrm{m}-400 \mu \mathrm{m}$

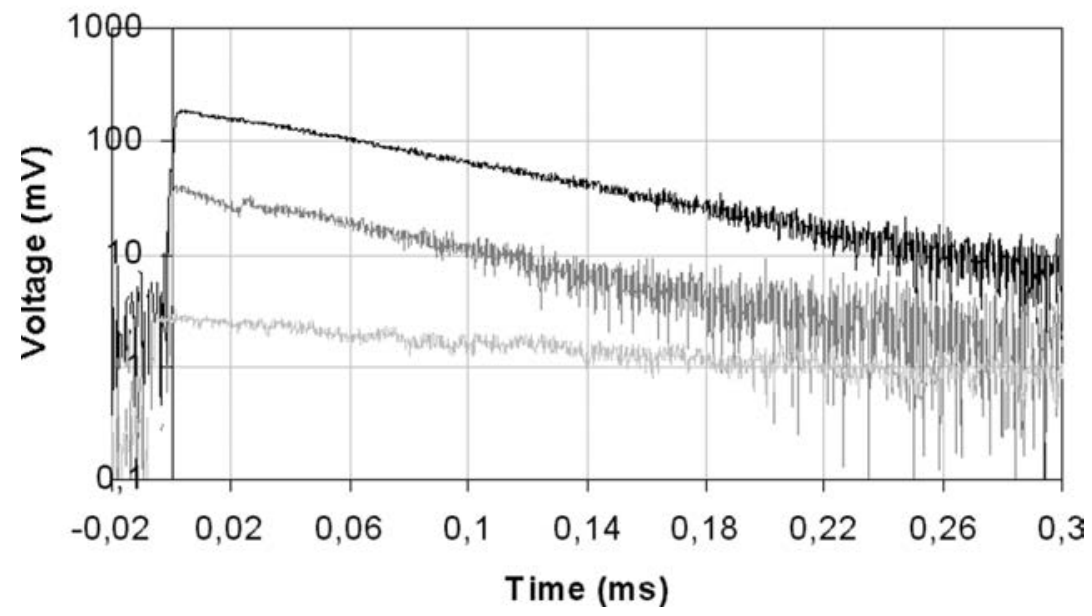

Figure 10. Comparison of pMUT generated voltage response versus silicon membrane diameter. 


\section{Voltage response under 1 Mohm load of pMUT (132 $\mu \mathrm{m}$ Silicon membrane diameter)}

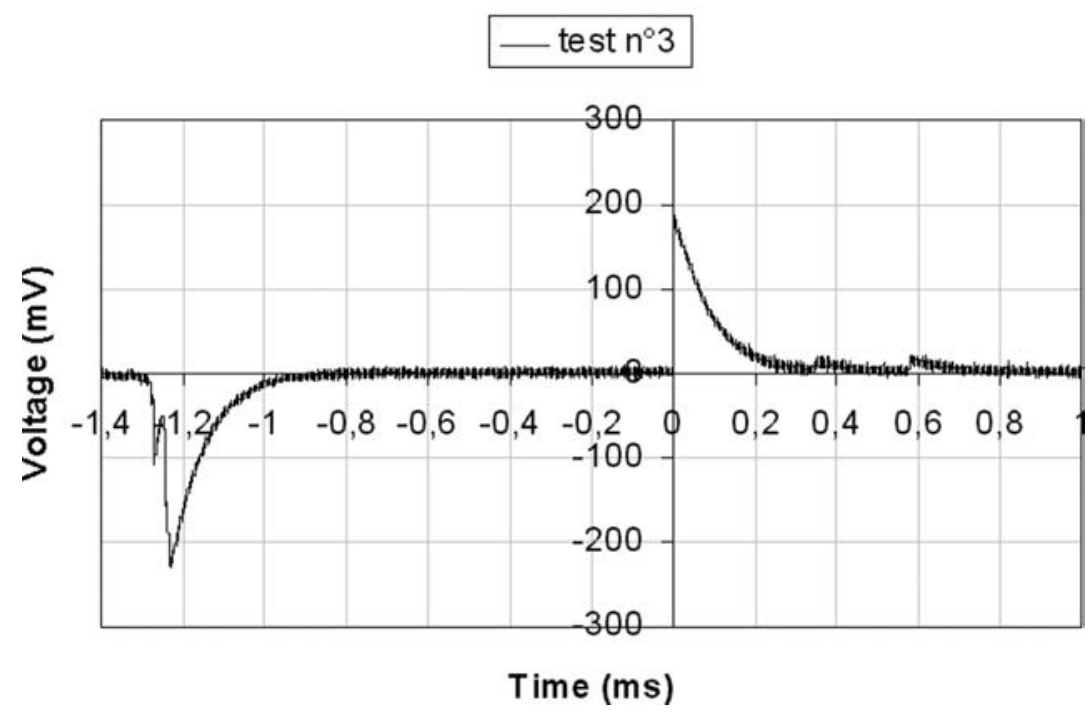

Figure 11. Generated voltage response of pMUT (132 $\mu \mathrm{m}$ silicon membrane diameter).

element method should clarify this point by taking into account the electrical load in the system.

Besides, Fig. 11 should demonstrate the pMUT bistability behaviour. The result of such state changes due to a hand shaking mechanical excitation is shown on Fig. 11. This graph clearly shows the effect of two state changes, i.e. two very sharp signals opposite and equal (larger than $180 \mathrm{mV}$ ), corresponding to the stresses inversion (compression to extension and extension to compression) and then the two respective flow of generated electrical charges.

\section{CONCLUSION}

We have described the fabrication of piezoelectric micro-machined ultrasonic transducers (pMUT) first dedicated to ultrasonic imaging applications that may be used as mechanical to electrical energy scavenger. The different pMUT devices have been tested using a weak mechanical excitation ranging from $0.5 \mathrm{~g}$ to $2 \mathrm{~g}$. The experiment results have shown two typical mechanical behaviours, linear (elastic) and non-linear (bistable). It is interesting to note that the pMUT device can generate electricity for both mechanical behaviours. The device will be tested using a vibration bench, allowing for an accurate definition of the device sensitivity and of its frequency cut (this operation mode is mainly quasistatic). These first experiments will help in the definition of process rules to 
establish a reliable fabrication procedure of such devices and also to improve the capability of such devices to provide a large amount of electrical energy for a given mechanical excitation for energy scavenging purpose. By the way, we assume (to the best of our knowledge) that we have proposed one of the smallest energy scavenging device.

\section{ACKNOWLEDGMENTS}

The authors wish to thank Dr. P. Delobelle for its help in the understanding of non linear mechanisms in film and membrane based devices.

\section{REFERENCES}

1. S. Roundy, P. Kenneth Wright, and J. M. Rabaey, Energy scavenging for wireless sensor networks with Special Focus on Vibrations, Kulwer Academic Publishers, 2004, I-4020-7663-0.

2. J. J. Bernstein, S. L. Finberg, K. Houston, L. C. Niles, H. D. Chen, L. E. Cross, K. K. Li, and K. Udayakumar, "Micromachined HighFrequency Ferroelectric Sonar Transducers," IEEE Trans. Ultrasonics, Ferroelectrics and Frequency Control 44(5), 960-969 (1997). 